\title{
Silencing of a large microRNA cluster on human chromosome 14q32 in melanoma: biological effects of mir-376a and mir-376c on insulin growth factor 1 receptor
}

Liron Zehavi ${ }^{1,2}$, Roi Avraham ${ }^{3}$, Aviv Barzilai ${ }^{4}$, Dalia Bar-llan ${ }^{4}$, Roy Navon ${ }^{6}$, Yechezkel Sidi ${ }^{1,{ }^{*+}}$, Dror Avni ${ }^{1{ }^{*+}}$ and Raya Leibowitz-Amit ${ }^{7 *}$

\begin{abstract}
Background: Metastatic melanoma is a devastating disease with limited therapeutic options. MicroRNAs (miRNAs) are small non coding RNA molecules with important roles in post-transcriptional gene expression regulation, whose aberrant expression has been implicated in cancer.

Results: We show that the expression of miRNAs from a large cluster on human chromosome $14 \mathrm{q} 32$ is significantly down-regulated in melanoma cell lines, benign nevi and melanoma samples relative to normal melanocytes. This miRNA cluster resides within a parentally imprinted chromosomal region known to be important in development and differentiation. In some melanoma cell lines, a chromosomal deletion or loss-of-heterozygosity was observed in the cis-acting regulatory region of this cluster. In several cell lines we were able to re-express two maternallyinduced genes and several miRNAs from the cluster with a combination of de-methylating agents and histone deacetylase inhibitors, suggesting that epigenetic modifications take part in their silencing. Stable over-expression of mir-376a and mir-376c, two miRNAs from this cluster that could be re-expressed following epigenetic manipulation, led to modest growth retardation and to a significant decrease in migration in-vitro. Bioinformatic analysis predicted that both miRNAs could potentially target the 3'UTR of IGF1R. Indeed, stable expression of mir-376a and mir-376c in melanoma cells led to a decrease in IGF1R mRNA and protein, and a luciferase reporter assay indicated that the 3'UTR of IGF1R is a target of both mir-376a and mir-376c.

Conclusions: Our work is the first to show that the large miRNA cluster on chromosome $14 \mathrm{q} 32$ is silenced in melanoma. Our results suggest that down-regulation of mir-376a and mir-376c may contribute to IGF1R over-expression and to aberrant negative regulation of this signaling pathway in melanoma, thus promoting tumorigenesis and metastasis.
\end{abstract}

Keywords: microRNA, Melanoma, IGF1R, mir-376a, mir-376c, Epigenetics

\section{Background}

Malignant melanoma is a devastating disease with a constantly increasing incidence worldwide and limited treatment options [1]. MicroRNAs (miRNAs) are small non

\footnotetext{
* Correspondence: ysidi48@gmail.com; droravni@msn.com; raya.LeibowitzAmit@sheba.health.gov.il

†Equal contributors

${ }^{1}$ Laboratory of Molecular Cell Biology, Cancer Research Center and Department of Medicine C, Sheba Medical Center, Tel Hashomer, Israel

${ }^{2}$ Sackler School of Medicine, Tel Aviv University, Tel Aviv, Israel

Full list of author information is available at the end of the article
}

coding RNA molecules that are generated within cells and play a role in post-transcriptional gene regulation [2]. It is becoming clear that aberrant expression of miRNAs has a role in cancerous transformation and progression [3]. Several miRNA-profiling studies in melanoma were published until now [4-6], but the picture emerging from these works is far from being clear.

A large miRNA cluster was recently shown to be downregulated in ovarian cancer, and eight miRNAs in this cluster were identified as potential tumor suppressor genes [7]. Lately, this cluster was also implicated in gastro-intestinal 
stromal tumors (GISTs) [8] and in gliomas [9]. Additionally, mir-127 from this cluster was shown to have tumor suppressor function in a bladder cancer model [10]. This miRNA cluster lies within a parentally imprinted chromosomal area designated Dlk1-Gtl2 in mouse or Dlk-Dio3 in human [11]. This area is of great developmental importance, exemplified by severe phenotypes associated with altered dosages of the genes within it in mice and humans [12]. The regulation of imprinting in this chromosomal locus is thought to be mediated, at least to some extent, by an intergenic differentially methylated region (IG-DMR) that is located centromeric to the imprinted region [13]. Indeed, this region was shown to be differentially methylated during embryonic development in humans [14]. Another regulatory region, located more telomeric, is designated 'MEG3-DMR'. Human studies performed on infants with uniparental dysomy of each of these DMRs imply that the IG-DMR and the MEG3-DMR function as imprinting control centers in the placenta and the body, respectively, with a hierarchical interaction for the methylation pattern in the body governed by the IG-DMR [15]. In mouse, deletion of IG-DMR from the maternally (but not the paternally) inherited chromosome causes bi-directional loss of imprinting of all genes in the cluster [11]. A meticulous characterization of all transcripts in this mouse locus demonstrated that the miRNAs within this cluster were exclusively expressed from the maternal chromosome. The other maternally expressed transcripts in this region (designated Meg3 and Meg8) were found to have exclusive patterns of expression, being detected only in brain, testis and skin [16]. Very recently, the expression of miRNAs from this region was found to be essential for maintaining full pluripotency of induced pluripotent stem cells [17].

Along the years, there have been few descriptions of chromosomal abnormalities in melanoma samples. 15 years ago, the translocation $\mathrm{t}(1 ; 14)(\mathrm{q} 21 ; \mathrm{q} 32)$ was found in several of 20 melanoma samples taken from patients [18], and more than a decade later this chromosomal region was again found to be aberrant in some melanoma cell lines [19]. Recently, Zhang et al. determined DNA copy number abnormalities in 283 miRNA genes in three different cancer types (namely ovary, breast and melanoma) using comparative genomic hybridization, and showed loss of hetrozygocity (LOH) of the 14q32 miRNA cluster in $20 \%$ of the melanoma cell lines examined [20]. Nonetheless, this cluster has not been specifically implicated in melanoma so far.

We show here that this large miRNA cluster is silenced in melanoma cell lines, benign nevi and melanoma samples, and present data suggesting that both genetic and epigenetic mechanisms may take part in this silencing. We provide data showing that re-expression of mir-376a and mir-376c, two miRNAs from this cluster, lead to attenuation of melanoma proliferation and migration. These two miRNAs target IGF1R, a tyrosine kinase receptor implicated in melanoma tumorigenesis and metastasis.

\section{Results}

To compare the miRNA expression pattern between normal and malignant melanocytes, two samples of miRNAs produced from normal human epidermal melanocytes (NHEM) and miRNAs from five melanoma cell lines were hybridized to a commercial miRNAs array, using commercial placental miRNAs as positive control (Additional file 1). An unsupervised cluster anlysis of the logarithm of the normalized values using the $\mathrm{k}$-means clustering algorithm showed that the two NHEM samples exhibit a very similar pattern of miRNAs expression, and that whereas the majority of miRNAs are not significantly altered between normal and malignant melanocytes (cluster \#3, Figure 1A), there are two distinct groups of miRNAs that are either up-regulated or down-regulated in melanoma vs. melanocytes (cluster \#2 and \#1, respectively, Figure $1 \mathrm{~A}$ ). The expression pattern of several miRNAs from the array was validated by quantitative RT-PCR, and all were found to exhibit similar expression patterns as in the array (Figure $1 \mathrm{~B}$ and results not shown).

Statistical analysis was undertaken to find miRNAs who exhibit the exact same pattern of expression (i.e. significant up-regulation or down-regulation) in all five melanoma cell lines compared to normal cells by using a student $t$-test with a $\mathrm{p}$ value $<0.0032$ (corrected for multiple comparisons with a false discovery rate of 0.05 ). Using this very stringent criterion, only 58 miRNAs were found to be significantly altered between normal melanocytes and all five malignant melanoma cell lines, out of which 57 were significantly down-regulated in melanoma. Interestingly, of these 57 miRNAs, 27 were mapped to a large bipartite miRNA aggregate on chromosome 14. This cluster resides within a parentally imprinted region on chromosome 14q32 known to be imperative in development and differentiation (Figure 1C) [12,15]. We therefore decided to focus our present work on miRNAs from this large aggregate. Table 1 depicts the expression pattern of all miRNAs from this cluster.

We next compared the expression pattern of miRNAs from benign melanocytic nevi and melanoma samples taken from parrafin-embedded tissues to miRNAs from normal melanocytes (Additional file 2). In general, the expression patterns of miRNAs from benign nevi and malignant melanoma were very similar. Interestingly, chromosome $14 \mathrm{q} 32$ miRNAs were significantly overrepresented in the cluster of miRNAs whose expression was significantly down-regulated in all melanoma and nevi. Whereas chromosome $14 \mathrm{q} 32$ miRNAs accounted for $7.6 \%$ of all miRNAs represented on the array (65 out of 851 ), they accounted for $23.5 \%$ of all the downregulated miRNAs (19 out of $81, \mathrm{p}<0.002$ using chi-square, comparing the observed frequencies vs the expected). 


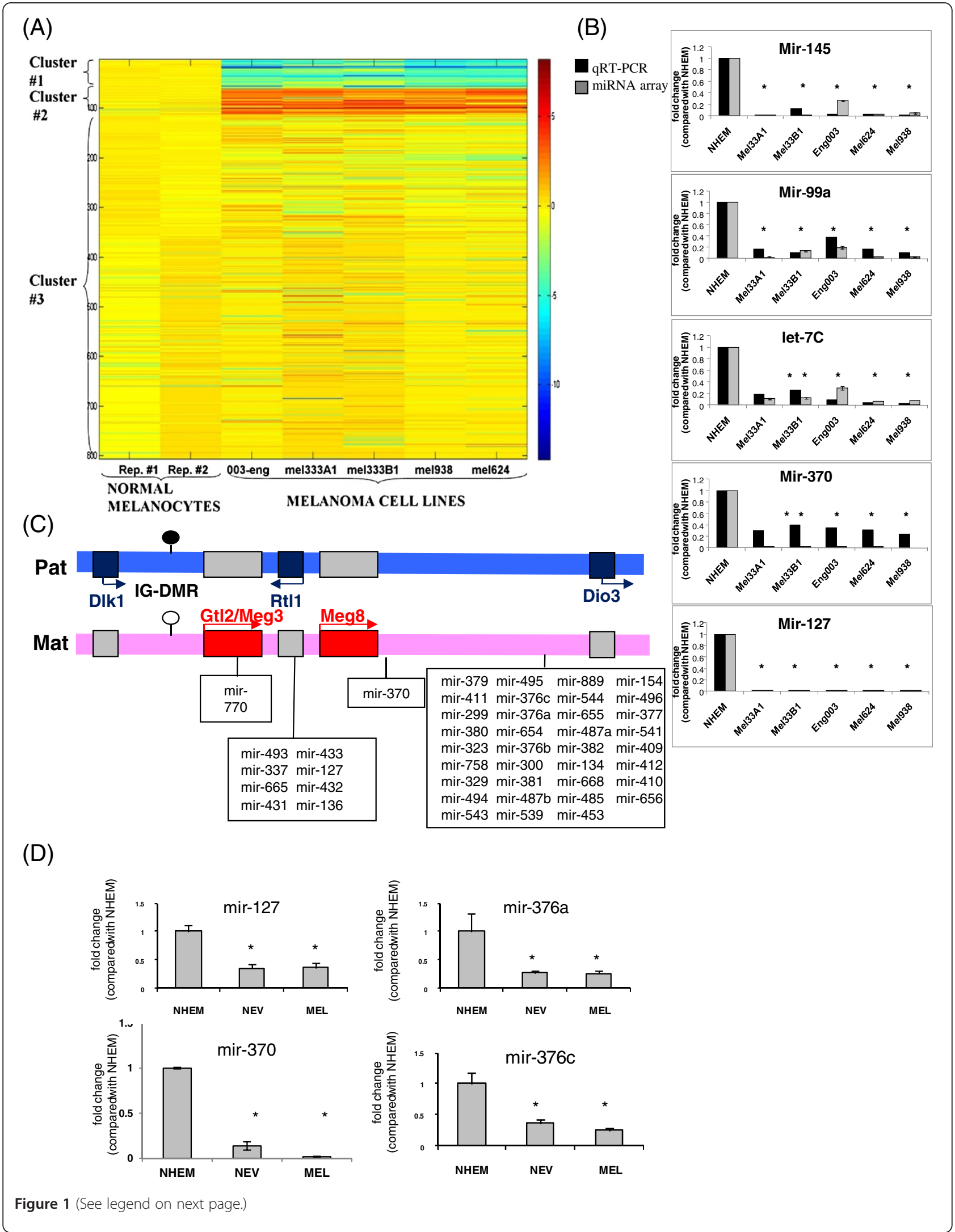


(See figure on previous page.)

Figure 1 The expression pattern of miRNAs in normal melanocytes and melanoma cell lines, and the organization of the 14q32 imprinted region. (A) Heat map representing a cluster analysis of the logarithm of the normalized values of $\sim 800$ miRNAs embedded on a commercial array in normal melanocytes (two samples) and five different melanoma cell lines. (B) The expression levels of five different miRNAs using qRT-PCR (black) or data obtained from the array (grey). Data is represented as mean \pm SEM, ${ }^{*}$ signifies $p<0.05$ (C) The organization of the Dlk-Gt12 region on human chromosome 14q32. The positions of miRNAs within this region are marked in rectangular boxes. The maternal allele is colored pink; the paternal allele is colored light-blue. The blue boxes signify paternally-expressed transcripts, and the red boxed signify maternally-expressed transcripts. The direction of transcription is marked with an arrow. The color of the hairpin at the IG-DMR illustrates the methylation status at the region; black - methylated, white hypo-methylated. (D) The expression levels of four miRNAs from the chromosome14q32-cluster in normal melanocytes (NHEM), benign nevi (NEV) and melanoma samples (MEL) using qRT-PCR. Data is normalized relative to NHEM and is represented as mean \pm SEM, ${ }^{*}$ signifies $p<0.05$.

We validated our micro-array results by performing qRT-PCR on miRNA produced from two different samples of NHEM, fifteen samples of benign nevi and seven samples of melanoma. All miRNAs examined were significantly down-regulated in nevi and melanoma relative to NHEM (Figure 1D and results not shown).

Previous work in mice showed that silencing of the maternally-expressed genes (coding for mRNAs and miRNAs) could result from deletion of the regulatory IG-DMR region [11], whereas in an in-vitro human model system, epigenetic modifications led to reexpression of a miRNA from this cluster [10]. We thus hypothesized that the apparent miRNA silencing from chromosome 14 could be the result of a chromosomal deletion of the regulatory region, epigenetic modifications or a combination of the two. Since the IG-DMR is a control element for all imprinted genes on the maternal chromosome [11], and since the miRNAs are thought to be transcribed only from the maternal chromosome [16], we first designed a DNA copy number assay using quantitative real time PCR with two different probes taken from the IG-DMR region. As expected, there were two copies of each of the two probes in the DNA taken from a healthy human subject, in the DNA of normal melanocytes and in the DNA of most of the melanoma cell lines. However, there were two melanoma cell lines that exhibited only one copy of the IG-DMR DNA, and no copies of either of the two probes were detected in another cell line (Table 2). These results suggest that $\mathrm{LOH}$ or complete absence of the IG-DMR locus could explain the miRNA silencing in some, but not all, of the melanoma cell lines.

Table 1 The expression levels of chromosome 14q32 miRNAs in melanoma

\begin{tabular}{|c|c|c|c|c|}
\hline \multicolumn{2}{|c|}{$\begin{array}{l}\text { miRNA that are } \\
\text { not expressed in } \\
\text { NHEM or in } \\
\text { melanoma cell } \\
\text { lines }(25)\end{array}$} & \multicolumn{2}{|c|}{$\begin{array}{c}\text { miRNA that are expressed in NHEM but not in } \\
\text { melanoma cell } \\
\text { lines }(31)\end{array}$} & \multirow{2}{*}{$\begin{array}{c}\text { miRNA that are } \\
\text { expressed in NHEM } \\
\text { and melanoma } \\
\text { cell lines (6) }\end{array}$} \\
\hline Mir-127-5p & Mir-487a & Mir-127-3p & Mir-381 & \\
\hline Mir-154* & Mir-493 & Mir-136* & Mir-382 & Mir-370 \\
\hline Mir-323-5p & Mir-496 & Mir-136 & Mir-409-3p & Mir-485-3p \\
\hline Mir-323-3p & Mir-539 & Mir-154 & Mir-409-5p & Mir-494 \\
\hline Mir-369-5p & Mir-541 & Mir-299-3p & Mir-410 & Mir-654-5p \\
\hline Mir-369-3p & Mir-541* & Mir-299-5p & Mir-411 & Mir-770-5p \\
\hline Mir-379* & Mir-544 & Mir-329 & Mir-411* & \multirow{7}{*}{$\begin{array}{l}\text { miRNAs with a } \\
\text { discrepancy in } \\
\text { expression between } \\
\text { two NHEM samples (3) }\end{array}$} \\
\hline Mir-380 & Mir-655 & Mir-337-3p & Mir-431 & \\
\hline Mir-380* & Mir-656 & Mir-337-5p & Mir-432 & \\
\hline Mir-412 & Mir-668 & Mir-376a & Mir-487b & \\
\hline Mir-432* & Mir-889 & Mir376a* & Mir-493* & \\
\hline Mir-433 & & Mir-376b & Mir-495 & \\
\hline Mir-453 & & Mir-376c & Mir-543 & \\
\hline \multirow[t]{3}{*}{ Mir-485-5p } & & Mir-377 & Mir-654-3p & Mir-300 \\
\hline & & Mir-377* & Mir-758 & Mir-431* \\
\hline & & Mir-379 & & Mir-665 \\
\hline
\end{tabular}

The expression levels of 65 miRNAs from the large miRNA cluster on human chromosome 14q32. 
Table 2 IG-DMR copy number in melanoma cell lines

\begin{tabular}{lll}
\hline \multicolumn{1}{c}{ Cell type } & Calculated Copy number \\
\hline Normal DNA & 2 \\
Normal melanocytes (NHEM) & 2 \\
Melanoma Cell lines & Mel624 & 2 \\
& $14 \mathrm{PA}$ & 2 \\
& $15 \mathrm{AY}$ & 2 \\
& mel33B1 & 2 \\
& Mel28 & 1 \\
& Eng003 & 1 \\
Mel33A1 & 0 \\
\hline
\end{tabular}

The calculated IG-DMR copy number as assessed using QPCR in normal human DNA, DNA from normal melanocytes and seven melanoma cell lines.

We then set out to study the expression of genes from this locus. The maternally expressed genes Meg3 and Meg8, known to be selectively expressed only in brain, skin and testis [16], were detected in normal but not in malignant melanocytes. The paternally expressed genes Rtl1 and Dio3 were detected in all cell lines (Figure 2A). To assess whether epigenetic modifications take part in silencing from this cluster, we searched for conditions and combinations of epigenetic modifiers (de-methylating agents and HDAC inhibitors) that might bring about re-expression of the maternal genes from this cluster. Both maternal transcripts could be re-expressed after several days of treatment with a combination of the demethylating agent 5 azacytidine (5-AZA) and the HDAC inhibitor valproic acid (VPA) but not with any of these agents alone (resuls not shown). The re-expression of the maternal expressed genes was observed in most of the cell lines examined, and was even more pronounced when using the HDAC inhibitor phenyl butyric acid (PBA; Figure 2B).

Re-expression of mir-127 was assessed using the same treatment conditions. Mir-127 could be induced between 8 to $30-$ fold using this treatment combination in all melanoma cell lines examined (Figure $2 \mathrm{C}$ ). To verify that the treatment indeed led to epigenetic modifications in the vicinity of the regulatory region of the 14q32-cluster, chromatin immunoprecipitation (ChIP) using an antiacetylated Histone 3 antibody was performed, showing that the addition of epigenetic modifiers increased the extent of histone acetylation in two different loci within the IG-DMR region and in another regulatory region located approximately $700 \mathrm{bp}$ upstream of the mir-127 locus [10] (Figure 2D), suggesting that re-expression of these miRNAs is a result of a true epigenetic alteration in the cells.

We utilized the micro-array platform to see which other chromosome-14-miRNAs could be induced using the combination of HDAC inhibitors and demethylating agents (Additional file 3). Interestingly, out of all 65 chromosome-14-miRNAs assessed in four melanoma cell lines, only five miRNAs were shown to be induced in any of the cell lines: mir-127-3p, mir-137, mir-376a (also designated mir-376a-3p), mir-376c and mir-485-3p. These five miRNAs, expressed in normal melanocytes, could not be further up regulated in these cells in response to epigenetic modifiers (Table 3). Four of these five miRNAs (mir-127-3p, mir-136, mir-376a and mir-376c) were found to be down-regulated but not entirely silenced in nevi and melanoma (Additional file 2 ). Results obtained with the more sensitive method of qRT-PCR verified that mir-376a, mir-376c and mir-136 can be significantly induced following treatment with epigenetic modifiers in most of the melanoma cell lines (Figure 2E and results not shown).

Mir-127 was previously shown to target BCL-6 in a bladder cancer model [10], so we first generated melanoma cell lines that ectopically express mir-127 in a stable manner. In our experimental system, mir-127 overexpression did not lead to a significant decrease in BCL-6 levels in melanoma cell lines, nor did it lead to a significant change in melanoma cell line proliferation or migration in vitro (results not shown). We therefore decided to focus on other miRNAs whose expression was shown to be down-regulated but not entirely absent in melanoma and as a first step generated melanoma cell lines that ectopically express either mir-376a or mir-376c (Figure 3A).

Cells over-expressing either mir-376a or mir-376c exhibited attenuated growth relative to pTER-transfected control cells (Figure 3B). This effect was modest yet statistically significant, leading to approximately $25-30 \%$ decrease in cell growth after 96 hours. This growth pattern was also observed using a micro-electronic biosensor system (designated 'real-time-cell-analyser', RTCA [21]) that allows realtime monitoring of cell growth in-vitro (Figure 3C). Cellular migration was monitored using an in-vitro transwell system. Mir-376a and mir-376c transfected cells showed significantly attenuated migration through a transwell membrane 24 hours after seeding relative to pTERtransfected control cells (Figure 3D). Migration was also monitored using the real-time-cell analyzer, this time assessing cell density following passage through a membrane as described in [22]. Whereas pTER-transfected control melanoma cells exhibited a time-dependent migration through the membrane, the mir-376a and mir-376c transfected cells showed almost no migration through the membrane within a $24 \mathrm{~h}$ period (Figure 3E).

Bioinformatic analysis using several web-based tools showed that miRNA-376a and miRNA-376c have putative binding sites at the 3'UTR of IGF1R (Figure 4A), a tyrosine kinase receptor long known to be implicated in melanoma tumorigenesis and progression [23]. The putative binding site of mir-376c is classified as '7mer8 mer binding', and that of mir-376a is classified as ' 8 mer binding'. Both putative binding sites are located within the first fifth of the IGF1R 3'UTR. Theoretically, mir- 
(A)

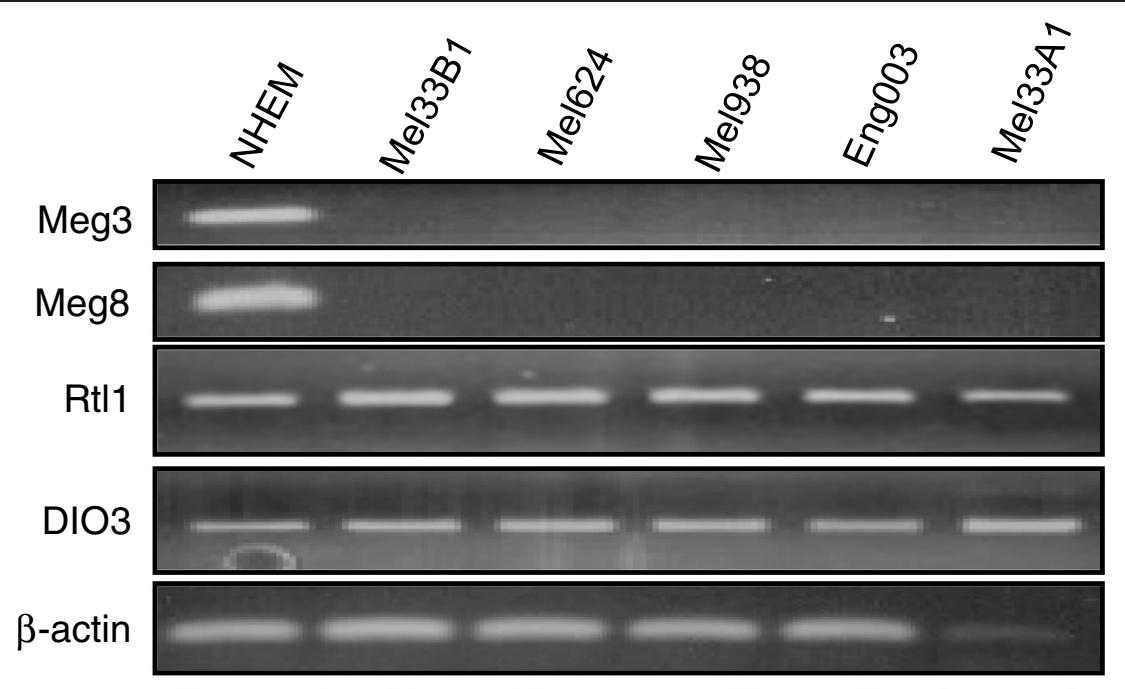

(B)
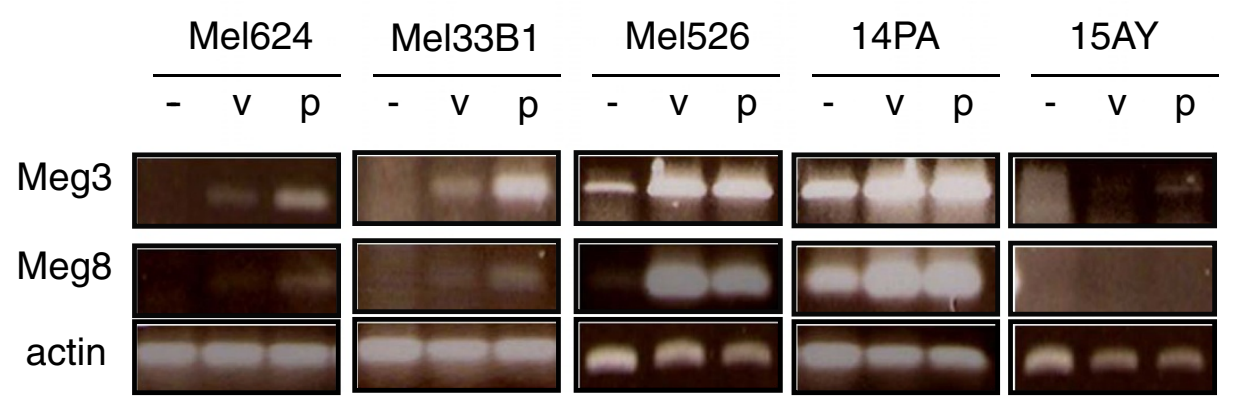

(C)

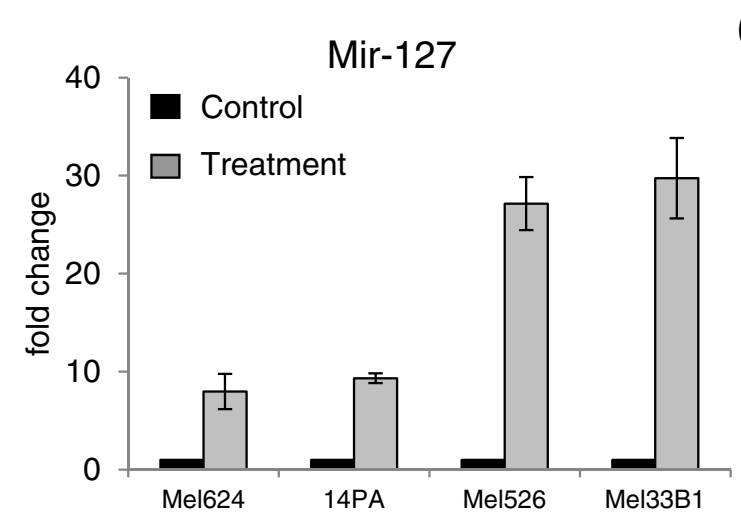

(D)

- Control Acetylated H3

$\square$ Treatment

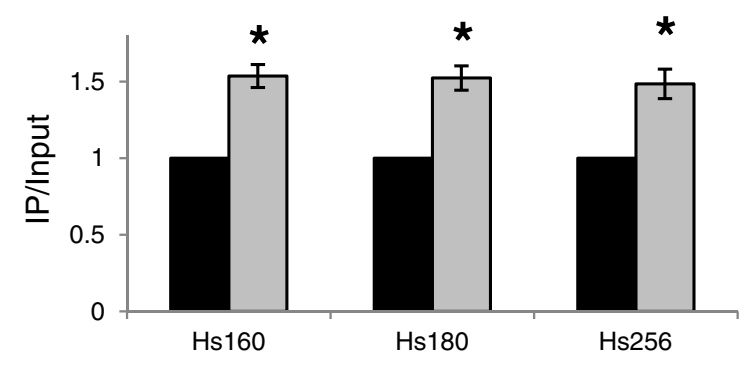

(E)
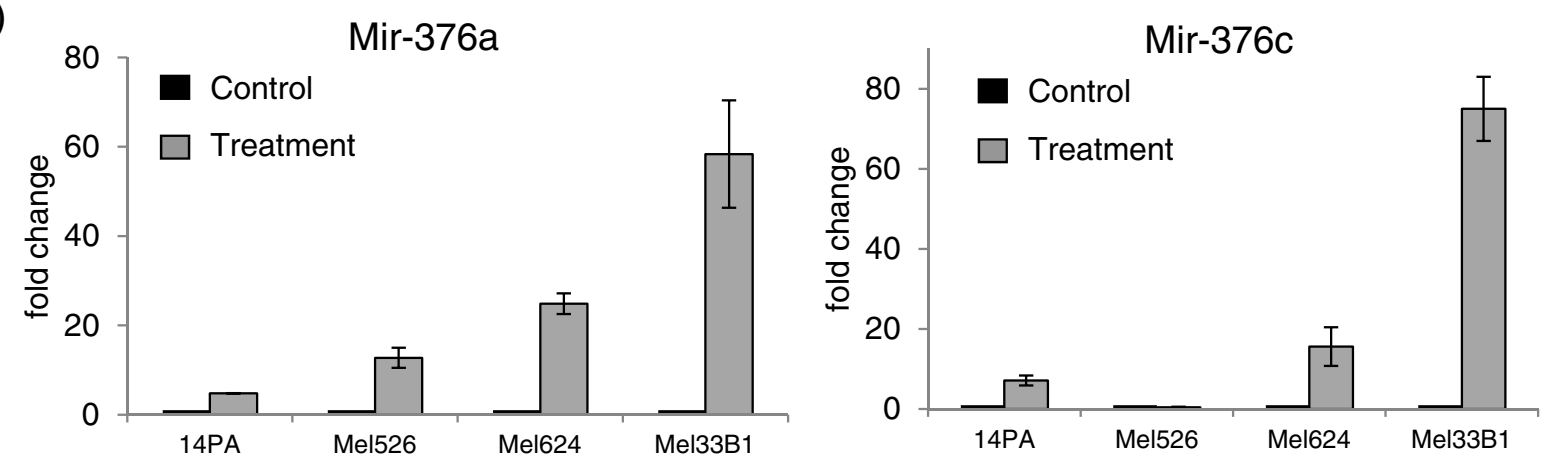

Figure 2 (See legend on next page.) 
(See figure on previous page.)

Figure 2 Re-expression of maternally expressed transcripts from chromosome 14q32 following treatment with epigenetic modifiers and its effect on histone acetylation. (A) The expression levels of the maternal (Meg3, Meg8) and paternal (Rt11, Dio3) genes in normal melanocytes (NHEM) and melanoma cell lines. (B) The expression levels of Meg3 and Meg8 following treatment with $10 \mu \mathrm{M}$ 5-AZA + 1.5 mM VPA (v) or $10 \mu M$ 5-AZA + 3 mM PBA (p) in five different cell lines. (C) The expression level of mir-127 in melanoma cells treated with epigenetic modifiers

(10 $\mu \mathrm{M}$ 5-Aza and $3 \mathrm{mM}$ PBA), as assessed by qRT-PCR and normalized relative to untreated cells. (D) ChIP assay of 14PA melanoma cells untreated or treated with $10 \mu \mathrm{M}$ 5-Aza and $3 \mathrm{mM}$ PBA. The normalized levels of chromosomal DNA at three different loci following immunoprecipitation with antiacetylated histone 3 in control cells and in cells treated with epigenetic modifiers are shown. Data is represented as mean \pm SEM, ${ }^{*}$ signifies $p<0.05$. (E) The expression level of mir-376a and mir-376c in cells untreated or treated with $10 \mu \mathrm{M}$ 5-Aza and 3 mM PBA.

376a could generate a stronger interaction with the IGF1R 3'UTR through additional nucleotide pairing beyond the "seed" sequence [24, 25] (Figure4A).

As expected, both mRNA and protein levels of IGF1R were higher in melanoma cell lines than in normal melanocytes (Figure 4B). Stable expression of mir-376a or mir$376 \mathrm{c}$ led to a decrease in IGF1R levels both at the mRNA and at the protein levels (Figure $4 \mathrm{C}$ ). In order to determine whether IGF1R is a direct target of miR-376a/c, we used a commercial plasmid containing the first $\sim 2800$ nucleotides of the IGF1R 3'UTR cloned downstream to the luciferase reporter gene. This vector was then introduced into melanoma cells over-expressing mir-376a, mir-376c or a control vector (designated pTER). Introduction of the IGF1R-3 'UTR-luciferase vector into pTER-transfected control cells led to a $\sim 40 \%$ decrease in the level of luciferase expression relative to the same cells following introduction with a control luciferase vector. This probably reflects the negative regulatory action of endogenous miRNAs within the melanoma cells on this 3'UTR. Introduction of the IGF1R-3'UTRluciferase vector into mir-376a-transfected or mir-376ctransfected cells led to a significant $\sim 83 \%$ and $\sim 65 \%$ decrease in the level of luciferase expression relative to the same cells following introduction with a control luciferase vector, respectively, indicating that the stable expression of both miRNAs leads to further significant down-regulation on the 3'UTR of IGF1R (Figure 4D), thus establishing IGF1R as a target of both mir-376a and mir-376c.

Table 3 Re-expression of chromosome 14q32 miRNAs following treatment with epigenetic modifiers

\begin{tabular}{|c|c|c|c|c|c|c|c|c|c|c|}
\hline \multirow[b]{3}{*}{$5 a z a+P B A$} & \multirow{2}{*}{\multicolumn{2}{|c|}{$\begin{array}{c}\text { Normal } \\
\text { Human } \\
\text { Melanocytes }\end{array}$}} & \multicolumn{8}{|c|}{ Melanoma Cell lines } \\
\hline & & & \multicolumn{2}{|c|}{ Mel33B1 } & \multicolumn{2}{|c|}{$14 \mathrm{PA}$} & \multicolumn{2}{|c|}{ Mel526 } & \multicolumn{2}{|c|}{ Mel624 } \\
\hline & - & + & - & + & - & + & - & + & - & + \\
\hline Mir-127 & 70.6 & 61.4 & UD & UD & 7.1 & 37.3 & UD & 9.5 & UD & UD \\
\hline Mir-136 & 52 & 44.4 & UD & UD & 7.9 & 30.8 & UD & UD & UD & UD \\
\hline Mir-376a & 100.1 & 75.4 & UD & UD & UD & 12.4 & UD & UD & UD & UD \\
\hline Mir-376c & 122.1 & 77.6 & UD & UD & UD & 10.4 & UD & UD & UD & UD \\
\hline Mir-485-3p & 12.7 & 18.4 & UD & 23.9 & 37.7 & 38.6 & 31.1 & 19.2 & UD & 16 \\
\hline
\end{tabular}

The expression levels of five chromosome-14q32 miRNAs in normal melanocytes and four melanoma cell lines as assessed by miRNA micro-array following treatment with epigenetic modifiers (10 $\mu \mathrm{M}$ 5-Aza and $3 \mathrm{mM}$ PBA); UD-undetected. The miRNAs with significant differences between treatment and control are bolded
To assess whether the down-regulation of IGF1R by mir$376 \mathrm{a}$ and mir-376c could account for the observed biological phenotype in these cells, IGF1R was pharmacologically inhibited using the commercially-available IGF1R inhibitor AG-1024 [26]. IGF1R inhibition by AG-1024 pheno-copied the decrease in migration seen following over-expression of either mir-376a or mir-376c using the same experimental system, in a dose-dependent manner (Figure 4E). The administration of AG-1024 to melanoma cells over-expressing either mir-376a or mir-376c did not lead to a further decrease in their migration (results not shown), suggesting that the IGF1R axis could not be further modulated to decrease migration. AG-1024 did not lead to decreased cellular proliferation in either the control cells or the cells over-expressing mir-376a or mir-376c, suggesting that the modest effect of these miRNAs on cellular growth is mediated through different mechanisms.

\section{Discussion}

We show here that miRNAs from a large cluster on chromosome 14q32 are significantly down-regulated or absent in melanoma cell lines, benign nevi and melanoma samples relative to normal melanocytes. This may suggest that their expression is lost along the transformation process of normal melanocytes into malignant cells. This resembles the well-known observation that the mutated form of B-RAF, which characterizes $40-60 \%$ of melanoma patients [27], can already be detected in benign pigmented nevi as well [28]. It is well-known that an acquired mutation in B-RAF is not sufficient for tumorigenesis [29]. We hypothesize that in a similar manner, the loss of expression of this miRNA cluster occurs already in the benign phase, but contributes to tumorigenesis and metastasis only upon the acquisition of additional genetic and cellular abnormalities.

The miRNA cluster on chromosome $14 \mathrm{q} 32$ has been shown to be down-regulated in ovarian cancer ([7], gastrointestinal stromal tumors (GIST) [8] and gliomas [9], and aberrations in chromosome 14 have been implicated in many types of cancer (reviewed in [9]). In fact, this region was already dubbed 'the largest miRNA tumor suppressor cluster [9]. A recent review summarized the growing body of literature connecting this region to cancer in many sites [30], yet until now, it has not been implicated in melanoma. 
(A)

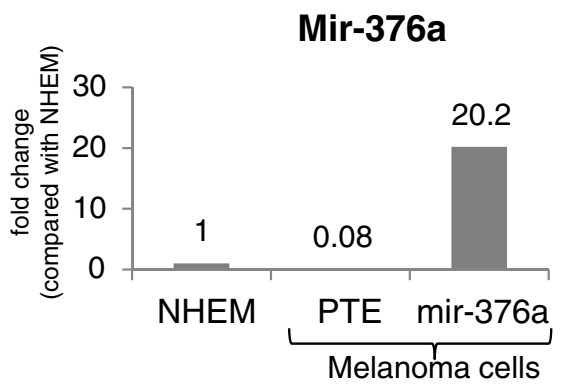

(B)

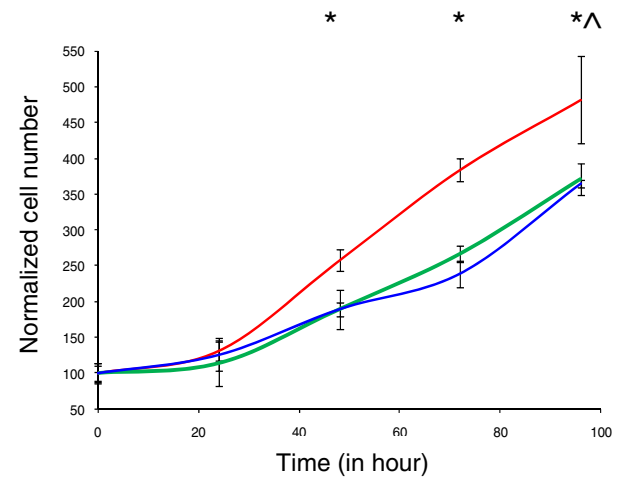

(D)

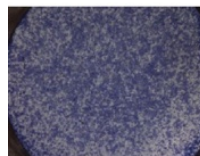

Transwell migration
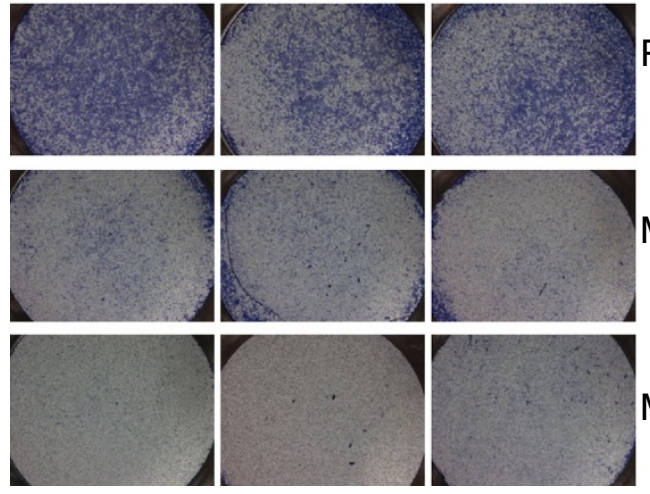

(C)

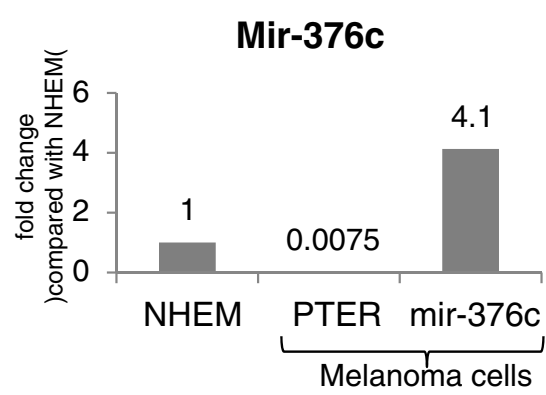

Real-Time proliferation

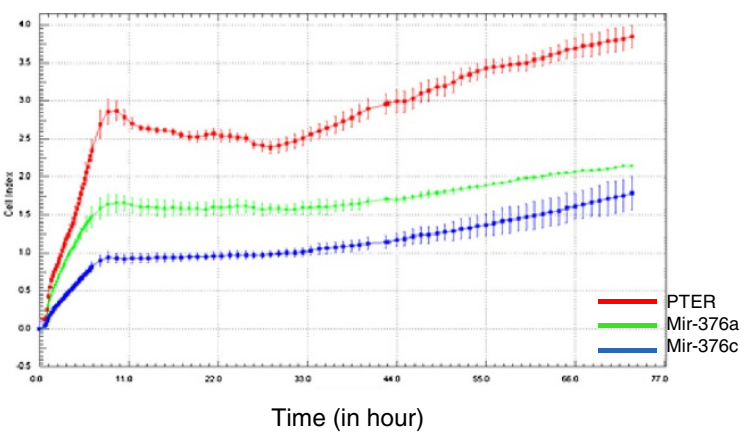

(E)

\section{Real-Time migration}

Pter

Mir-376a

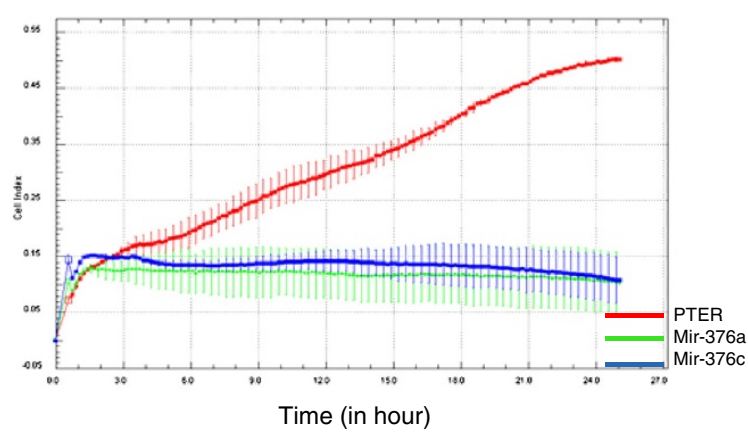

Mir-376c

Figure 3 The effect of stable expression of mir-376a and mir-376c on the proliferation and migration of melanoma cells. (A) qRT-PCR analysis of mel33B1 melanoma cells after stable transfection with an empty pTER vector or vectors containing either mir-376a (left) or mir-376c (right). The relative expression levels are numerically depicted. (B) The growth of mel33B1 melanoma cell lines transfected with pTER, mir-376a and mir-376c was assessed using the crystal-violet method for $96 \mathrm{~h}$. ${ }^{*}$ signifies $p<0.05,{ }^{*} \wedge$ signifies $p<0.08$ (C) The growth of mel33B1 melanoma cell lines transfected with pTER, mir-376a and mir-376c was assessed using the Xcellience ${ }^{\text {TM }}$ real-time system. (D) The migration of these three cell lines was assessed using the in-vitro transwell method. Representative micrographs of the transwell membrane are seen. This experiment was repeated three times. (E) Cellular migration was assessed using the Xcellience ${ }^{\text {TM }}$ real-time system within a $24 \mathrm{~h}$ period.

Several analyses of miRNA arrays in melanoma have recently been published [4-6], all in agreement that only several miRNAs are differentially expressed between normal melanocytes and melanoma cell lines or samples. Neither work pointed to the almost complete disappearance of miRNA expression from this cluster. This is most likely due to methodological differences between the different works.
Some of the chromosome-14q32-miRNAs were expressed in very low amounts in normal melanocytes, thus perhaps 'evading' detection with miRNA arrays of lower sensitivity than the one used in our current work, whereas at least ten miRNAs from the cluster were expressed in higher levels than the median expression level in the array. It is important to emphasize that the expression pattern of chromosome- 
$(A)_{\text {Human }} \begin{aligned} & \cdots \\ & \text { GUUCCUAGGACUUCUUCAUGGGUCUUACAGUUCUAUGUUAGACCAUGAAACAUUUGCAUACACAUCGU }\end{aligned}$ Chimpanzee GUUCCUAGGACUUCUUCAUGGGUCUUACAGUUCUAUGUUAGACCAUGAAACAUUUGCAUACACAUCGU Mouse GUUACUAGGACUUCUUCAUGGGUCUCUCAGUUCUAUGUUAGACCGUGAAACAUUUGCAUACACAUCGU Rat GUUACUAGGACUUCUUCAUGGGUCUCUCAGUUCUAUGUUAGACCCUGAAACAUUUGCAUACGCAUCGU Rabbit GUUACUGGGACUUUCUCAUGGGUCUUACAGUUCUAUGUUAGACCGUGAAGCAUUUGCAUACACAUCAU Cat GUUACUAGGACUUCUUCAUGGGUCUUACAGUUCUAUGUUAGACCAUGAAACAUUUGCAUACACAUCGU Lizard AUUAUUGAGACUUC-AAAAGGGUCUGGCAGUUCUAUGUUAGACCACGGAUCAUUUGCAUACACAUUGU Chicken UUAUUAUUAAGACUUCUCGAAGGGUCUUGCAGUUCUAUGUUAGACCAUGGAUCAUUUGCAUACACAUUGU Mir-376C seed

1162-1168 of IGF1R-3'UTR 5'CAUGGGUCUUACAGUUCUAUGUU...

Human

Chimpanzee

Mouse

Rat

Rabbit

Cat

Lizard $\ldots . .1290 \ldots . . . . .1300 \ldots 1310 \ldots . \ldots 1330 \ldots . \ldots$ UUGUUCUUGAUCUUUGUGGAUUUAAUCUAU- - GAAAACCUUCAGGUCCA - CCC - UCUCCCCUU UUGUUCUUGAUCUUUGUGGAUUUAAUCUAU--GAAAACCUUCAGGUCCA- CCC-UCUCCCCUU UUGUUCUUUAUCUUUGUGGAUUUAAUCUAU - - GAAA - CUUUCAGGUCUACCCC - UUCUUCCUU UUGUUCUUUAUCUUUGUGGAUUUAAUCUAU - - GAAA - CUUUCAGGUCUA - CCC - UUCUUCCUU UCGUUCCUUCUCUUUGUGGAUUUAAUCUAU - - GAAA - UCUUCAGGUCUCUG - CUUUCCUCCCU UUGUCCUUUAUCUUUGUGGAUUUAAUCUAU - - GAAAACCUUCAGGUCUA- CCCUCCUUCCCUC UUGUUCUUUAUCUUUGUGGAUUUAAUCUAUAAGAAAUACUUCAGGUCUA- CCCCCCCUUCCUU

$$
\text { Mir-376a seed }
$$

1307-1314 of IGF1R-3'UTR 5'UUGUGGAUUUAA-UCUAUGAA

$$
\text { | || || || |||||| }
$$

hsa-miR-376a
(B)
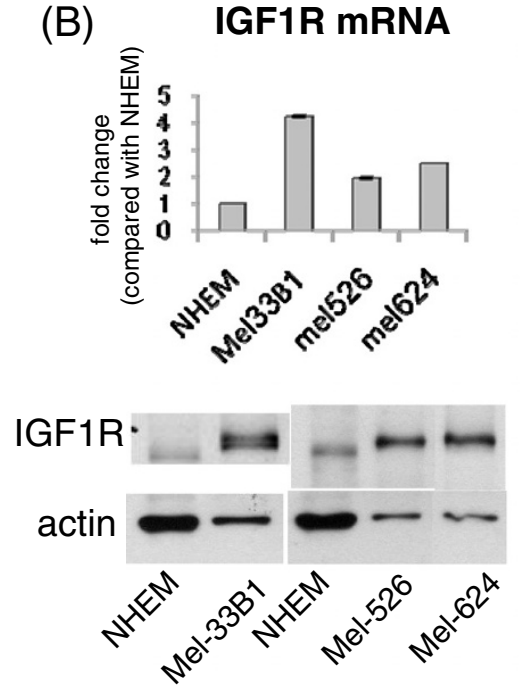

(C)

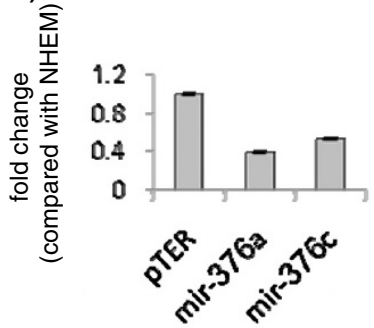

IGF1R

actin

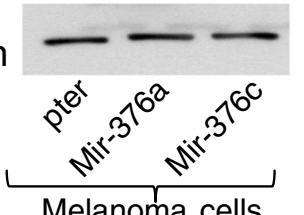

(D)

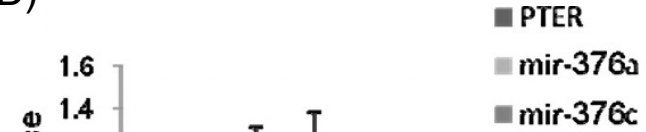

mir-376c
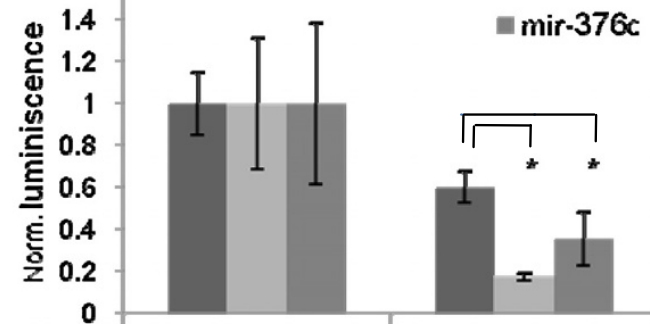

con

IGF1R 3'A

(E)
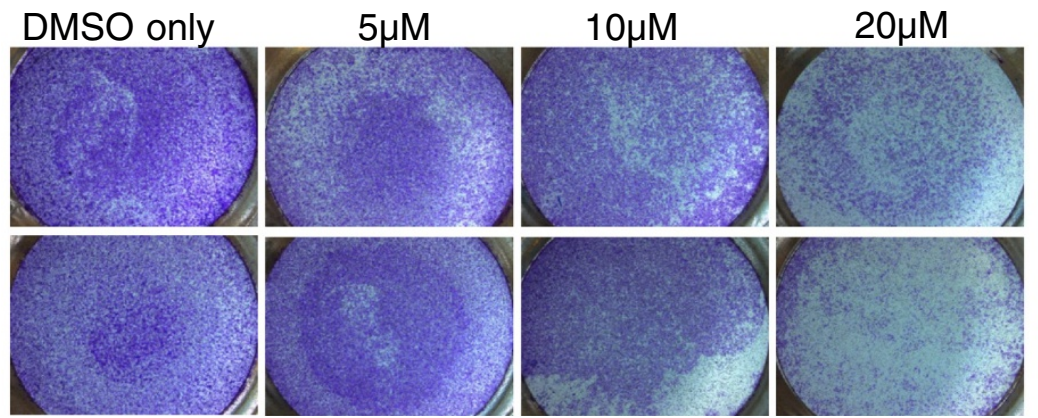

Figure 4 (See legend on next page.) 
(See figure on previous page.)

Figure 4 Establishment of IGF1R as a target of mir-376a/c. (A) The 3'UTR of the IGF1R gene showing potential binding sites for mir-376a/c (marked in grey). The sequence conservation from human to lizard in the vicinity of mir-376c and 376a seed sequences and the putative interaction of the miRNAs and the mRNA are shown (taken from TargetScan at http://www.targetscan.org/). (B) IGF1R mRNA and protein levels in NHEM and several melanoma cell lines using GRT-PCR and Western blot, respectively. (C) IGF1R mRNA and protein levels in pTER-transfected and mir-376a/c-transfected mel33B1 melanoma cells using qRT-PCR and Western blot, respectively. (D) Melanoma cell lines stably transfected with PTER, mir-376a or mir-376c were transiently transfected with a control-luciferase vector or with a vector containing luciferase attached to an element of the 3'UTR of the IGF1R gene containing the putative binding sited for mir-376a/c (designated IGF1R 3'A). The ratio of expression of luciferase/renilla was normalized relative to control-transfected cells for each of the cell lines. ${ }^{*}$ signifies $p<0.05$ using two-way ANOVA. (E) The migration of control pTER-transfected melanoma cells was assessed in the absence and in the presence of varying doses of AG-1024 using the invitro transwell method. Representative micrographs of the transwell membrane are seen. This experiment was repeated three times.

14q32-miRNAs and maternal transcripts were consistently seen in all normal melanocyte samples examined by us from several different batches, using both the micro-array technique and qRT-PCR. Indeed, Stark et al. characterized the 'melanoma miRNAome' by performing deep sequencing of cell lines derived from normal melanocytes, melanoblasts, melanoma and a large congenital nevus, and also demonstrated that Chromosome-14q32-miRNAs are expressed in normal melanocytes but not in any melanoma cell lines [31], in complete agreement with our current work. Moreover, Philippidou et al. also observed that both mir-127-3p and mir-376c are down-regulated in a metastatic cell line relative to their expression in the primary tumor from the same patient [5], again in agreement with our current observations.

Genetic analysis in mice elegantly showed that a maternal deletion of the IG-DMR region could lead to a shutdown of the expression of genes from the maternal chromosome, thus rendering the expression pattern from this chromosome to be 'paternal-like' [11]. Our copy number assay indicates that $\mathrm{LOH}$ of the IG-DMR or complete absence of two copies of this region occurs in less than half of the cell lines examined. Our results are in line with published results, showing that $20 \%$ of the melanoma cell lines exhibit copy number losses in miRNA genes in chromosome 14q32 [20]. Nonetheless, LOH of the IGDMR region is clearly not the sole mechanism underlying this miRNA cluster shut-down. Interestingly, an LOH spanning approximately $1.1 \mathrm{Mb}$ in the same region on chromosome 14q32 was found to characterize many cases of neuroblastoma [32], a neoplasm derived from neural crest cells, the precursor cells from which mature melanocytes develop as well.

Recent studies suggested that the expression of Dlk1Dio3 transcribed miRNAs is essential for maintaining full pluripotency of induced pluripotent stem cells (iPSCs), and that this expression is in fact the most significant discriminator between fully pluripotent and partially pluripotent inducible cells $[17,33]$. These works, albeit descriptive in nature, again point to the cardinal role of this large miRNA locus on the fine interplay between differentiation, pluripotency and transformation.
We observed that only a combination of de-methylating agents and HDAC inhibitors (designated 'epigenetic modifiers' in short) could lead to re-expression of two maternally expressed genes and only very few miRNAs from this cluster. We could not find a correlation between the number of copies of the IG-DMR region and the potential or the extent of re-expression following treatment, suggesting that epigenetically 'switching on' a silenced allele is feasible whether there are two alleles in the cell or only one.

The observed increase in the levels of acetylatedhistone-3 DNA in three different loci within the regulatory regions following treatment with epigenetic modifiers suggests that epigenetic alterations takes part in silencing of this cluster. The observation that only a few miRNAs from the cluster could be re-expressed after treatment with epigenetic modifiers was somewhat surprising. Four of these miRNAs (namely mir-127-3p, mir136, mir-376a and mir-376c) were shown to be downregulated but not completely silenced in nevi and melanomas. These results, taken together, suggest that the regulation of the expression of miRNAs from this cluster is complex and multi-leveled. Whereas previous results suggest that the IG-DMR is an important regulatory 'switch' in this region [34], our work suggest that it is by no means the only one. One can postulate that specific miRNAs within this large cluster have their own individual 'switches', and indeed such a switch has been suggested for mir-127 [10], also shown to be up regulated in our work in response to epigenetic modifiers.

Ectopic expression of mir-376a and mir-376c had a modest yet significant effect on cell growth, but a profound effect on cellular migration in-vitro. Indeed, it has already been suggested that melanoma proliferation and migration are controlled through different regulatory circuits [35]. The Insulin growth factor 1 receptor was recently shown to be constitutively activated in melanoma cells in an autocrine fashion [36]. Insulin-like growth factor 1 (IGF-1) was shown by others to significantly increase melanoma cell migration in-vitro through activation of the IGF1R. IGF1-stimulated migration required PI3K activation but was independent of MAPK/ERK 
signaling [37]. In our experimental system, IGF1R levels were higher in melanoma cell lines than in normal melanocytes, and the ectopic expression of mir-376a and mir-376c led to down-regulation of the receptor. Luciferase reporter assays indicate that, as bioinformatically predicted, mir-376a and mir-376c directly target IGF1R. Pharmacological inhibition of IGF1R pheno-copied the decrease in migration seen following mir-376a and mir376c over-expression, suggesting that down-modulation of the IGF1R signaling pathway may be responsible for the observed anti-migratory effect of these miRNAs in melanoma cell lines.

Other miRNAs have been shown to down-regulate IGF1R. For example, mir-145, a known tumor-suppressor-miRNA, was shown to inhibit the IGF1R axis by targeting both IRS-1 and IGF1R [38]. Recently, mir-493 (curiously also located on chromosome 14q32) was shown to be capable of inhibiting liver metastasis in a colon cancer model by targeting IGF1R [39]. Nonetheless, the inhibition of IGF1R by mir-376a and mir-376 has not been described before.

\section{Conclusions}

We show here that a large miRNA cluster on chromosome $14 \mathrm{q} 32$ is silenced in malignant melanoma. This cluster has been implicated in many cancers, as well as in differentiation and in determination of pluripotency, but not in melanoma so far. This silencing may involve genetic or epigenetic mechanisms, and can partly be reverted in-vitro using epigenetic modifiers such as demethylating agents and HDAC inhibitors. Re-expression of two miRNAs from this cluster, namely mir-376a and 376-c, attenuate melanoma proliferation and migration. Both these miRNAs target IGF1R.

IGF1R has already been implicated in melanoma almost 20 years ago [40], and data concerning its exact role in the pathogenesis of this disease is rapidly accumulating (reviewed in [23]). Eight years ago the IGF1/IGF1R pair was shown to lead to melanoma migration [37], and in fact IGF1R was recently identified as a potential target in melanoma using a phosphoproteomic screen [41]. Last, in-vitro work showed that resistance to B-RAF inhibition could be overcome by simultaneously co-targeting MEK and IGF1R/ PI3K, and that indeed IGF1R levels are increased in human tumor sample following the acquisition of resistance to BRAF inhibition, consistent with a role for IGF1R/PI3Kdependent survival in the development of such resistance [42]. More specifically, the possibility of targeting the IGF1R by siRNAs in B-RAF-mutated melanoma cells was also already suggested several years ago [43].

The work presented here demonstrates that mir-376a and mir-376c negatively regulate IGF1R, and suggests that aberrations in this regulatory mechanism, in the form of down-regulation of mir-376a/c, take part in melanoma progression and metastasis. In lieu of growing interest in this pathway in relation to B-RAF inhibition, our work may, in the future, contribute to further understanding of the phenomenon of resistance to B-RAF inhibition.

\section{Methods \\ Cells cultures and reagents}

Melanoma cell lines were generated directly from metastatic melanoma lesions of patients at the Surgical branch of the NIH (mel526, mel624, mel938, mel33A1, mel33B1; $[44,45])$ or at the 'Ella institute for melanoma research' at the Sheba Medical center (eng-003, 14PA, 15AY [46]). The cell lines were grown in DMEM medium supplemented with $10 \%$ fetal bovine serum (FBS), 1\% Penicillin-Streptomycin antibiotics, 1\% L-glutamine and 2.5\% HEPES solution (Biological Industries, Kibbutz Beit Haemek, Israel). Normal human epidermal melanocytes (NHEM) were purchased (three different batches throughout the period of research) from Promocell (C-12400; Promocell, Germany) and grown in melanocyte growth medium (C-24010; Promocell) according to manufacturer's instructions. NHEM were maintained in culture for up to 5 cycles.

AG-1024 (a commercially-available IGF1R inhibitor) was purchased from Calbiochem- EMD Biosciences (La Jolla, CA, USA).

\section{Cloning}

Both mir-376a and mir-376c pre-miRNAs were cloned into the pTER plasmid $[47,48]$. It is to note that there are two miRNA genes, mir-376a-1 and mir-376a-2, coding identical mature miRNAs, that are indistinguishable. Briefly, both sense and anti-sense oligos of the pre-miRNA were synthetically synthesized (Sigma, Israel). Sequences were taken from the miRBase data base as follows:

Mir-376a sense primer:

\section{5'TAAAAGGUAGATTCTCCTTCTATGAGTACATTA TTTATGATTAATCATAGAGGAAAATCCACGTTT TC-3'}

Mir-376c sense primer:

\section{5'-AAGGTGGATATTCCTTCTATGTATGTAT TTATGGTTAAACATAGAGGAAATTCCAC GTTTT-3}

GATC (the complementary sequence to BglII digested) was added to the 5 ' end of the sense oligo, and TCGA (the complementary sequence to HindIII digested) was added to the anti-sense oligo. Sense and anti sense oligos were Annealed and ligated into the pTER vector digested with BglII and HindIII. 
The IGF1R-3'UTR Lucifrase reporter plasmid (clone A HmiT009523-MT01) and control plasmid (no 3'UTR; CmiT000001-MT01) were purchased from GeneCopoeia, Inc. (Rockville, MD).

\section{Generation of stable melanoma cell lines}

Cells were transfected with purified DNA plasmids with the Lipofectamine 2000 Transfection Reagent (Invitrogen, Carlsbad, CA), according to the manufacturer protocol. 24 hours after transfection, Zeocin antibiotic $(300 \mu \mathrm{g} / \mathrm{ml})$ was added to the cells for selection. Following selection, the stable ectopic expression of mir-376a/c was repeatedly assessed using qRT-PCR.

\section{Tumor samples}

Formalin-fixed-parrafin-embedded (FFPE) samples of benign nevi or primary cutanous melanoma were obtained from the pathology institute at the Sheba Medical Center. The initial diagnosis of melanoma and the histological type was verified by a pathologist on the hematoxylin-eosin-stained slides, performed on the first and/or last sections of the sample. The tumor or nevus was macro-dissected from the slide in the cases in which the sample contained normal tissues as well, based on demarcations delineated by the pathologist. The study was approved by the ethics committee of Sheba Medical Center and conducted in adherence to the Declaration of Helsinki protocols.

\section{RNA extraction}

Total RNA was extracted from cell lines using Ambion mirVana $^{\mathrm{TM}}$ miRNA Isolation Kit (Ambion, Austin, TX). Total RNA from 10 sections of $5 \mu \mathrm{m}$ FFPE tissues was extracted using the Qiagen miRNeasy FFPE kit (Qiagen, Germantown, MD). Quantity and quality were evaluated using a Nanodrop ND-2000 (Thermo Scientific, Waltham, MA) with inclusion criteria of A260/A280 $\geq 1.8$. For positive control, a commercial sample of placental miRNAs was used (Ambion, Austin, TX).

miRNA micro-array experimentation and analyses

miRNA expression profiling was performed using Agilent' Human miRNA Micro-array system V2 and later V3 (Agilent Technologies, Santa Clara, CA) with probe sets for approximately 850 human miRNAs (taken from the 'miRBase' database) according to the manufacturer's protocol . In brief, $100 \mathrm{ng}$ of total RNA were fluorescentlylabeled with Cyanine 3-pCp, and hybridized onto the arrays for $18-20 \mathrm{~h}$ at $55{ }^{\circ} \mathrm{C}$. Slides were scanned in an Agilent micro-array scanner G2565BA and the images obtained were processed with Feature Extraction Software 9.5.3.1 (Agilent, Santa Clara, CA). Cluster analysis was done on the normalized, log transformed values with the k-means algorithm using the MATLAB software (MathWorks, Natick, MA).

\section{Quantitative real time PCR}

\section{MiRNA}

Quantification of miRNAs by TaqMan MicroRNA assays (Applied Biosystems, Carlsbad, CA) was carried out using 10 ng of RNA. Target miRNA expression was normalized between samples based on the expression levels of Rnu19 or Rnu48. The $\Delta \Delta C T$ method was used to calculate the expression values.

\section{mRNA}

IGF1R mRNA levels was assessed with the TaqMan ${ }^{\circledR}$ Gene Expression Assay (ID Hs99999020_m1 IGF1R). Gene expression was normalized between different samples based on the values of Rplpo expression.

\section{Copy number assay}

Total cellular DNA was extracted using genomic DNA extraction kit (iNtRON biotechnology, Seongnam, Korea). Quantification of DNA by TaqMan Copy Number assays was carried out using $10 \mathrm{ng}$ of DNA with the primers Hs03889256_cn, Hs03874180_cn, Hs03877160_cn (Applied Biosystems, Carlsbad, CA). Genomic Rnase P region served as a reference assay. Analyzes were done using the 'CopyCaller $^{\mathrm{TM}}$ software' (Applied Biosystems, Carlsbad, CA).

\section{Determination of mRNA levels by RT-PCR}

Reverse transcription-polymerase chain reaction (RT-PCR) was performed using the Verso thermo-scientific kit (Thermo-Scientific, Waltham, MA). PCR primers are listed (Table 4).

\section{Treatment with epigenetic modifiers}

Cells were seeded at $50 \%$ confluence $8 \mathrm{hr}$ prior to treatment with 5-Aza-2'-deoxycytidine (5-Aza $10 \mu \mathrm{M}$; Sigma-Aldrich, Rehovot, Israel) and valproic acid (VPA $1.5 \mathrm{mM}$; SigmaAldrich, Rehovot, Israel) or phenylbutyric acid (PBA $3 \mathrm{mM}$; Sigma-Aldrich, Rehovot, Israel). The drugs were continuously administered by replacing the medium every $24 \mathrm{~h}$ for 5 days.

\section{Chromatin-immunoprecipitation (ChIP) assay}

\14PA melanoma were cells treated with 5-Aza and PBA and subjected to a ChIP assay using a modified protocol as decribed in [49]. In short, cells were

Table 4 Primer sequences used for assessment of mRNA levels by qRT-PCR

\begin{tabular}{llc}
\hline Gene name & \multicolumn{1}{c}{ Forward } & \multicolumn{1}{c}{ Reverse } \\
\hline -actin & CCTGGCACCCAGCACAAT & GCCGATCCACACGGAGTACT \\
Meg3 & TGCGGAAGAGGCCCTGAT & GTCCAGAGTCTCTGGGTCCA \\
Meg8 & CAGTGTTGCCTGGGTCTGA & ATCCCCTTGAAAGAGCAGGA \\
Rt11 & CCTGCCCTGCGTCAGAACCG & TGCTGGAGACAGGGAGGCGT \\
Dio3 & TGGTGGTCGGAGAGGGCGAG & CGGTTGTCGTCGGACACGCA \\
\hline
\end{tabular}


incubated with formaldehyde, washed, centrifuged and resuspended in 1\% SDS-containing buffer and then sonicated. Extracts were immunoprecipitated with antiacetylated histone $\mathrm{H} 3$ antibody (Millipore, Billerica, MA) overnight at $4^{\circ} \mathrm{C}$. Quantitative analysis was performed by real-time PCR with TaqMan primers as follows: Hs03889256_cn and Hs03874180_cn, both located within the $8 \mathrm{~kb}$-long IG-DMR region (approximately $15 \mathrm{~kb}$ upstream of Gtl2 and $70 \mathrm{~kb}$ downstream of the Dlk1 promotor); and Hs03877160_cn, located approximately 700 bp upstream of mir-127 (Applied Biosystems, Carlsbad, CA).

\section{Luciferase assay}

Luciferase assay was performed $48 \mathrm{~h}$ post transfection with a control vector or a vector containing part of the 3'UTR of the IGF1R using the Dual Luminescence Assay Kit (GeneCopoeia, Inc., Rockville, MD) as described by the manufacturer.

\section{Determination of protein expression level by western blotting (WB)}

WB was performed using monoclonal primary specific antibodies (IGF1R $\beta$ c20 CS-713, Santa Cruz Biotechnology, USA, and Beta Actin AC-15, Abcam, UK) as perviously described [50].

\section{Cell growth and migration in-vitro}

\section{Crystal violet}

Melanoma cells $\left(5 \times 10^{3}\right)$ were seeded in a 96-well plates and viable cell counts were monitored from seeding time to $96 \mathrm{~h}$. The cells were fixated with ethanol $70 \%$ and stained with crystal violet $0.1 \%$. The color was extracted using $1 \%$ triton $\mathrm{x}-100$ and absorption was read at $550 \mathrm{~nm}$. Each experiment was performed in quadruplicate, and repeated at least three times.

\section{Transwell migration}

Melanoma cells $\left(2 \times 10^{5}\right)$ were seeded in the upper wells of a Transwell migration system on ThinCerts ${ }^{\mathrm{TM}}$ inserts with $8-\mu \mathrm{m}$ membranes (Greiner-bio-one, Frickenhausen, Germany) in DMEM supplemented with $0.1 \%$ FBS. The lower well contained the same medium with 10\% FBS. After 24 hours of incubation, the upper well content, which contained non-migrating cells, was vigorously removed using cotton swabs. The cells that migrated through the membranes were fixated with $70 \%$ cold Ethanol, stained with crystal violet $0.1 \%$ and photographed using the light microscope. Each experiment was performed in triplicate, and repeated three times.

\section{Real-time-cell-analyser $\left(\right.$ RTCA $\left.^{\circledR}\right)$}

Melanoma cells were seeded in the $x$ CELLigence ${ }^{\mathrm{TM}} \mathrm{DP}$ system (Roche Diagnostics $\mathrm{GmbH}$, Mannhein, Germany) and incubated for 1-5 days. For monitoring growth, data were collected every $20 \mathrm{~min}$ automatically by the analyzer as described in [21]. For verification, a cellular growth curve was also obtained using the crystal violet technique described above. For monitoring migration, cells were seeded in the upper chamber in the normal culture medium of the respective cell line with $0.1 \%$ FBS. This upper chamber was then placed on the lower part of the CIM-device containing growth medium supplemented with $10 \%$ FBS as an attractant. Migration of the cells was followed for $24 \mathrm{~h}$ by tracking changes of the impedance signal in a CIM-plate measured on the opposing side of the membrane as described in [22]. Each experiment was performed in duplicates and repeated twice.

\section{Statistical analysis}

Statistical significance was determined using the Student's $t$-test or using two-way ANOVA. For a single comparison, a p-value $<0.05$ was considered significant. For multiple comparisons, a p-value $<0.0032$ was used, taking into account multiple comparisons using the method of false detection rate (FDR).

\section{Additional files}

Additional file 1: The expression levels of miRNAs in normal melanocytes and melanoma cell lines.

Additional file 2: The expression levels of miRNAs in normal melanocytes, benign nevi and melanoma samples.

Additional file 3: The expression levels of miRNAs in melanoma cell lines in response to epigenetic modifiers.

\section{Abbreviations}

ChIP: Chromatin immunoprecipitation; DMR: Differentially methylated region; HDAC: Histone de-acetylase; IG-DMR: Intergenic differentially methylated region; IGF1R: Insulin growth factor 1 receptor; LOH: Loss of heterozygosity; miRNA: micro-RNA; NHEM: Normal human epidermal melanocytes; RTCA: Real-time cell analyzer

Competing interests

There are no financial or non-financial competing interests to declare.

\section{Author contributions}

LZ performed the molecular biology and tissue culture experiments; RA performed the micro-array experiments (with $L Z$ ); $A B$ and DB performed the experiments with the pathological material; RN performed the bioinformatic and statistical analyses; LZ, YS, DA and RLA designed the experiments, analyzed the data and prepared the manuscript. All authors read and approved the final manuscript.

\section{Ackowledgements}

We would like to thank Dr. Tami Rubinek for her generous gift of AG-1024 and Dr. Guy Amit for his help in the bioinformatical analysis of the microarray results. This work was supported by grants from the Israeli Cancer Association (ICA), The 'Morasha' program of the Israel Science Foundation 
(grant No. 1499/09) and the Chief Scientist Office at the Israeli Ministry of Health.

Dr. Leibowitz-Amit is a recipient of a Dr. Edward H. Kass fellowship from the American Physicians Fellowship for Medicine in Israel, a recipient of the 'Stewart Rahr - MRA Young Investigator Award', and a member of the 'Talpiot Medical Leadership program' at the 'Sheba Medical Center'.

\section{Author details}

${ }^{1}$ Laboratory of Molecular Cell Biology, Cancer Research Center and Department of Medicine C, Sheba Medical Center, Tel Hashomer, Israel. ${ }^{2}$ Sackler School of Medicine, Tel Aviv University, Tel Aviv, Israel. ${ }^{3}$ Department of Biological Regulation, Weizmann Institute of Science, Rehovot, Israel. ${ }^{4}$ Institute of Pathology, Sheba Medical Center, Tel Hashomer, Israel. ${ }^{5}$ Department of Dermatology, Sheba Medical Center, Tel Hashomer, Israel. ${ }^{6}$ Agilent Laboratories, Tel Aviv, Israel. 'Institute of Oncology, Sheba Medical Center, Tel Hashomer 52621, Israel.

\section{Received: 7 February 2012 Accepted: 25 May 2012}

Published: 2 July 2012

\section{References}

1. Gray-Schopfer V, Wellbrock C, Marais R: Melanoma biology and new targeted therapy. Nature 2007, 445:851-857

2. Valencia-Sanchez MA, Liu J, Hannon GJ, Parker R: Control of translation and mRNA degradation by miRNAs and siRNAs. Genes Dev 2006, 20:515-524.

3. Molnar V, Tamasi V, Bakos B, Wiener Z, Falus A: Changes in miRNA expression in solid tumors: an miRNA profiling in melanomas. Semin Cancer Biol 2008, 18:111-122.

4. Segura MF, Belitskaya-Levy I, Rose AE, Zakrzewski J, Gaziel A, Hanniford D, Darvishian F, Berman RS, Shapiro RL, Pavlick AC, et al: Melanoma MicroRNA signature predicts post-recurrence survival. Clin Cancer Res 2010, 16:1577-1586.

5. Philippidou D, Schmitt M, Moser D, Margue C, Nazarov PV, Muller A, Vallar L, Nashan D, Behrmann I, Kreis S: Signatures of microRNAs and selected microRNA target genes in human melanoma. Cancer Res 2010, 70:4163-4173.

6. Caramuta S, Egyhazi S, Rodolfo M, Witten D, Hansson J, Larsson C, Lui WO MicroRNA expression profiles associated with mutational status and survival in malignant melanoma. J Invest Dermatol 2010, 130:2062-2070.

7. Zhang L, Volinia S, Bonome T, Calin GA, Greshock J, Yang N, Liu CG, Giannakakis A, Alexiou P, Hasegawa K, et al: Genomic and epigenetic alterations deregulate microRNA expression in human epithelial ovarian cancer. Proc Natl Acad Sci USA 2008, 105:7004-7009.

8. Haller F, von Heydebreck A, Zhang JD, Gunawan B, Langer C, Ramadori G, Wiemann S, Sahin O: Localization- and mutation-dependent microRNA (miRNA) expression signatures in gastrointestinal stromal tumours (GISTs), with a cluster of co-expressed miRNAs located at 14q32.31. J Pathol 2010, 220:71-86.

9. Lavon I, Zrihan D, Granit A, Einstein O, Fainstein N, Cohen MA, Cohen MA, Zelikovitch B, Shoshan Y, Spektor S, et al: Gliomas display a microRNA expression profile reminiscent of neural precursor cells. Neuro Oncol 2010, 12:422-433.

10. Saito Y, Liang G, Egger G, Friedman JM, Chuang JC, Coetzee GA, Jones PA: Specific activation of microRNA-127 with downregulation of the protooncogene BCL6 by chromatin-modifying drugs in human cancer cells. Cancer Cell 2006, 9:435-443.

11. Lin SP, Youngson N, Takada S, Seitz H, Reik W, Paulsen M, Cavaille J, Ferguson-Smith AC: Asymmetric regulation of imprinting on the maternal and paternal chromosomes at the Dlk1-Gtl2 imprinted cluster on mouse chromosome 12. Nat Genet 2003, 35:97-102.

12. da Rocha ST, Edwards CA, Ito M, Ogata T, Ferguson-Smith AC: Genomic imprinting at the mammalian Dlk1-Dio3 domain. Trends Genet 2008, 24:306-316.

13. Takada S, Paulsen M, Tevendale M, Tsai CE, Kelsey G, Cattanach BM, FergusonSmith AC: Epigenetic analysis of the Dlk1-Gtl2 imprinted domain on mouse chromosome 12: implications for imprinting control from comparison with Igf2-H19. Hum Mol Genet 2002, 11:77-86.

14. Geuns E, De Temmerman N, Hilven P, Van Steirteghem A, Liebaers I, De Rycke M: Methylation analysis of the intergenic differentially methylated region of DLK1-GTL2 in human. Eur J Hum Genet 2007, 15:352-361.

15. Kagami M, O'Sullivan MJ, Green AJ, Watabe Y, Arisaka O, Masawa N, Matsuoka K, Fukami M, Matsubara K, Kato F, et al: The IG-DMR and the MEG3-DMR at human chromosome 14q32.2: hierarchical interaction and distinct functional properties as imprinting control centers. PLoS Genet 2010, 6:e1000992.
16. Hagan JP, O'Neill BL, Stewart CL, Kozlov SV, Croce CM: At least ten genes define the imprinted Dlk1-Dio3 cluster on mouse chromosome 12qF1. PLoS One 2009, 4:e4352.

17. Stadtfeld M, Apostolou E, Akutsu H, Fukuda A, Follett P, Natesan S, Kono T, Shioda T, Hochedlinger K: Aberrant silencing of imprinted genes on chromosome $12 \mathrm{qF} 1$ in mouse induced pluripotent stem cells. Nature 2010, 465:175-181.

18. Grammatico P, Catricala C, Potenza C, Amantea A, Roccella M, Roccella F, Eibenschutz L, Del Porto G: Cytogenetic findings in 20 melanomas. Melanoma Res 1993, 3:169-172.

19. Okamoto I, Pirker C, Bilban M, Berger W, Losert D, Marosi C, Haas OA, Wolff K, Pehamberger $\mathrm{H}$ : Seven novel and stable translocations associated with oncogenic gene expression in malignant melanoma. Neoplasia 2005, 7:303-311.

20. Zhang L, Huang J, Yang N, Greshock J, Megraw MS, Giannakakis A, Liang S, Naylor TL, Barchetti A, Ward MR, et al: microRNAs exhibit high frequency genomic alterations in human cancer. Proc Natl Acad Sci USA 2006, 103:9136-9141.

21. Solly $K$, Wang $X, X u X$, Strulovici B, Zheng W: Application of real-time cell electronic sensing (RT-CES) technology to cell-based assays. Assay Drug Dev Technol 2004, 2:363-372.

22. Greiner M, Kreutzer B, Jung V, Grobholz R, Hasenfus A, Stohr RF, Tornillo L, Dudek J, Stockle M, Unteregger G, et al: Silencing of the SEC62 gene inhibits migratory and invasive potential of various tumor cells. Int J Cancer 2011, 128:2284-2295.

23. Capoluongo E: Insulin-like growth factor system and sporadic malignant melanoma. Am J Pathol 2011, 178:26-31.

24. Grimson A, Farh KK, Johnston WK, Garrett-Engele P, Lim LP, Bartel DP: MicroRNA targeting specificity in mammals: determinants beyond seed pairing. Mol Cell 2007, 27:91-105.

25. Doench JG, Sharp PA: Specificity of microRNA target selection in translational repression. Genes Dev 2004, 18:504-511.

26. Parrizas M, Gazit A, Levitzki A, Wertheimer E, LeRoith D: Specific inhibition of insulin-like growth factor-1 and insulin receptor tyrosine kinase activity and biological function by tyrphostins. Endocrinology 1997, 138:1427-1433.

27. Flaherty KT, McArthur G: BRAF, a target in melanoma: implications for solid tumor drug development. Cancer 2010, 116:4902-4913.

28. Zalaudek I, Guelly C, Pellacani G, Hofmann-Wellenhof R, Trajanoski S, Kittler H, Scope A, Marghoob AA, Longo C, Leinweber B, et al: The dermoscopical and histopathological patterns of nevi correlate with the frequency of BRAF mutations. J Invest Dermatol 2011, 131:542-545.

29. Michaloglou C, Vredeveld LC, Soengas MS, Denoyelle C, Kuilman T, van der Horst CM, Majoor DM, Shay JW, Mooi WJ, Peeper DS: BRAFE600-associated senescence-like cell cycle arrest of human naevi. Nature 2005, 436:720-724

30. Benetatos L, Voulgaris $E$, Vartholomatos G: DLK1-MEG3 imprinted domain microRNAs in cancer biology. Crit Rev Eukaryot Gene Expr 2012, 22:1-15.

31. Stark MS, Tyagi S, Nancarrow DJ, Boyle GM, Cook AL, Whiteman DC, Parsons PG, Schmidt C, Sturm RA, Hayward NK: Characterization of the Melanoma miRNAome by Deep Sequencing. PLoS One 2010, 5:e9685.

32. Hoshi M, Otagiri N, Shiwaku HO, Asakawa S, Shimizu N, Kaneko Y, Ohi R, Hayashi $Y$, Horii A: Detailed deletion mapping of chromosome band $14 q 32$ in human neuroblastoma defines a 1.1-Mb region of common allelic loss. Br J Cancer 2000, 82:1801-1807.

33. Liu L, Luo GZ, Yang W, Zhao X, Zheng Q, Lv Z, Li W, Wu HJ, Wang L, Wang XJ, Zhou Q: Activation of the imprinted Dlk1-Dio3 region correlates with pluripotency levels of mouse stem cells. J Bio/ Chem 2010, 285:19483-19490.

34. Seitz H, Royo H, Bortolin ML, Lin SP, Ferguson-Smith AC, Cavaille J: A large imprinted microRNA gene cluster at the mouse Dlk1-Gtl2 domain. Genome Res 2004, 14:1741-1748.

35. Levy C, Khaled M, lliopoulos D, Janas MM, Schubert S, Pinner S, Chen PH, Li S, Fletcher AL, Yokoyama S, et al: Intronic miR-211 assumes the tumor suppressive function of its host gene in melanoma. Mol Cell 2010, 40:841-849.

36. Molhoek KR, Shada AL, Smolkin M, Chowbina S, Papin J, Brautigan DL, Slingluff $\mathrm{CL}$ Jr: Comprehensive analysis of receptor tyrosine kinase activation in human melanomas reveals autocrine signaling through IGF1R. Melanoma Res 2011, 21:274-284.

37. Neudauer CL, McCarthy JB: Insulin-like growth factor I-stimulated melanoma cell migration requires phosphoinositide 3-kinase but not extracellular-regulated kinase activation. Exp Cell Res 2003, 286:128-137.

38. La Rocca G, Badin M, Shi B, Xu SQ, Deangelis T, Sepp-Lorenzinoi L, Baserga R: Mechanism of growth inhibition by MicroRNA 145: the role of the IGFI receptor signaling pathway. J Cell Physiol 2009, 220:485-491. 
39. Okamoto K, Ishiguro T, Midorikawa Y, Ohata H, Izumiya M, Tsuchiya N, Sato A, Sakai $\mathrm{H}$, Nakagama H: miR-493 induction during carcinogenesis blocks metastatic settlement of colon cancer cells in liver. EMBO J 2012, 31:1752-1763.

40. Resnicoff M, Coppola D, Sell C, Rubin R, Ferrone S, Baserga R: Growth inhibition of human melanoma cells in nude mice by antisense strategies to the type 1 insulin-like growth factor receptor. Cancer Res 1994, 54:4848-4850.

41. Tworkoski K, Singhal G, Szpakowski S, Zito Cl, Bacchiocchi A, Muthusamy V, Bosenberg M, Krauthammer M, Halaban R, Stern DF: Phosphoproteomic screen identifies potential therapeutic targets in melanoma. Mol Cancer Res 2011, 9:801-812.

42. Villanueva J, Vultur A, Lee JT, Somasundaram R, Fukunaga-Kalabis M, Cipolla AK Wubbenhorst B, Xu X, Gimotty PA, Kee D, et al: Acquired resistance to BRAF inhibitors mediated by a RAF kinase switch in melanoma can be overcome by cotargeting MEK and IGF-1R/PI3K. Cancer Cell 2010, 18:683-695.

43. Yeh AH, Bohula EA, Macaulay VM: Human melanoma cells expressing V600E B-RAF are susceptible to IGF1R targeting by small interfering RNAs. Oncogene 2006, 25:6574-6581.

44. Restifo NP, Marincola FM, Kawakami Y, Taubenberger J, Yannelli JR, Rosenberg SA: Loss of functional beta 2-microglobulin in metastatic melanomas from five patients receiving immunotherapy. J Natl Cancer Inst 1996, 88:100-108.

45. Lehmann F, Marchand M, Hainaut P, Pouillart P, Sastre X, Ikeda H, Boon T, Coulie PG: Differences in the antigens recognized by cytolytic $T$ cells on two successive metastases of a melanoma patient are consistent with immune selection. Eur J Immunol 1995, 25:340-347.

46. Besser MJ, Treves AJ, Itzhaki O, Hardan I, Nagler A, Papa MZ, Catane R, Winkler E, Shalmon-Zifroni B, Schachter J: Adoptive cell therapy for metastatic melanoma patients: pre-clinical development at the Sheba Medical Center. Isr Med Assoc J 2006, 8:164-168.

47. Brummelkamp TR, Bernards R, Agami R: A system for stable expression of short interfering RNAs in mammalian cells. Science 2002, 296:550-553.

48. van de Wetering M, Oving I, Muncan V, Pon Fong MT, Brantjes $H$, van Leenen D, Holstege FC, Brummelkamp TR, Agami R, Clevers H: Specific inhibition of gene expression using a stably integrated, inducible smallinterfering-RNA vector. EMBO Rep 2003, 4:609-615.

49. Avni D, Yang H, Martelli F, Hofmann F, ElShamy WM, Ganesan S, Scully R, Livingston DM: Active localization of the retinoblastoma protein in chromatin and its response to $\mathrm{S}$ phase DNA damage. Mol Cell 2003, 12:735-746.

50. Lerman G, Avivi C, Mardoukh C, Barzilai A, Tessone A, Gradus B, Pavlotsky F, Barshack I, Polak-Charcon S, Orenstein A, et al: MiRNA expression in psoriatic skin: reciprocal regulation of hsa-miR-99a and IGF-1R. PLoS One 2011, 6:e20916.

doi:10.1186/1476-4598-11-44

Cite this article as: Zehavi et al:: Silencing of a large microRNA cluster on human chromosome 14q32 in melanoma: biological effects of mir$376 \mathrm{a}$ and mir-376c on insulin growth factor 1 receptor. Molecular Cancer 2012 11:44.

\section{Submit your next manuscript to BioMed Central and take full advantage of:}

- Convenient online submission

- Thorough peer review

- No space constraints or color figure charges

- Immediate publication on acceptance

- Inclusion in PubMed, CAS, Scopus and Google Scholar

- Research which is freely available for redistribution 